\title{
Nociceptin/Orphanin FQ Decreases Glutamate Transmission and Blocks Ethanol-Induced Effects in the Central Amygdala of Naive and Ethanol-Dependent Rats
}

\author{
Marsida Kallupi ${ }^{1,2}$, Florence P Varodayan', Christopher S Oleata', Diego Correia ${ }^{1,3}$, George Luu' and \\ Marisa Roberto*,' \\ 'Committee on the Neurobiology of Addictive Disorders, The Scripps Research Institute, La Jolla, CA, USA; ${ }^{2}$ School of Pharmacy, Pharmacology \\ Unit, University of Camerino, Camerino, Italy; ${ }^{3}$ Department of Pharmacology, Universidade Federal do Paraná, Jardim das Américas, Curitiba, \\ Paraná, Brazil
}

\begin{abstract}
The central nucleus of the amygdala (CeA) mediates several addiction-related processes and nociceptin/orphanin FQ (nociceptin) regulates ethanol intake and anxiety-like behaviors. Glutamatergic synapses, in the CeA and throughout the brain, are very sensitive to ethanol and contribute to alcohol reinforcement, tolerance, and dependence. Previously, we reported that in the rat CeA, acute and chronic ethanol exposures significantly decrease glutamate transmission by both pre- and postsynaptic actions. In this study, using electrophysiological techniques in an in vitro CeA slice preparation, we investigated the effects of nociceptin on glutamatergic transmission and its interaction with acute ethanol in naive and ethanol-dependent rats. We found that nociceptin $(100-1000 \mathrm{nM})$ diminished basal-evoked compound glutamatergic receptor-mediated excitatory postsynaptic potentials (EPSPs) and spontaneous and miniature EPSCs (s/mEPSCs) by mainly decreasing glutamate release in the CeA of naive rats. Notably, nociceptin blocked the inhibition induced by acute ethanol ( $44 \mathrm{mM}$ ) and ethanol blocked the nociceptin-induced inhibition of evoked EPSPs in CeA neurons of naive rats. In neurons from chronic ethanol-treated (ethanol-dependent) rats, the nociceptin-induced inhibition of evoked EPSP amplitude was not significantly different from that in naive rats. Application of [Nphe I]Nociceptin ( I-13)NH2, a nociceptin receptor (NOP) antagonist, revealed tonic inhibitory activity of NOP on evoked $\mathrm{CeA}$ glutamatergic transmission only in ethanol-dependent rats. The antagonist also blocked nociceptin-induced decreases in glutamatergic responses, but did not affect ethanol-induced decreases in evoked EPSP amplitude. Taken together, these studies implicate a potential role for the nociceptin system in regulating glutamatergic transmission and a complex interaction with ethanol at CeA glutamatergic synapses. Neuropsychopharmacology (2014) 39, I08I-1092; doi:I0.1038/npp.20 I3.308; published online 27 November 20I3
\end{abstract}

Keywords: amygdala; glutamate; alcohol; nociceptin; NOP receptor; electrophysiology

\section{INTRODUCTION}

Many studies, conducted using a variety of experimental techniques, indicate that the amygdala has a crucial role in drug dependence and ethanol-reinforcing actions (Koob and Le Moal, 2001; Koob et al, 1998). Specifically, the central nucleus of the amygdala (CeA) is considered critical in mediating the behavioral effects of ethanol (Eckardt et al, 1998; Pich et al, 1995; Rassnick et al, 1993; Roberts et al, 1996). In particular, alcohol dependence is defined by the emergence of a negative emotional state mediated in part by the recruitment of pro- and antistress peptides in the amygdala (Koob, 2008; Koob and Le Moal, 2008; Roberto et al, 2012).

*Correspondence: Dr M Roberto, Committee on the Neurobiology of Addictive Disorders, The Scripps Research Institute, SP30-II50, 10550 North Torrey Pines Road, La Jolla, CA 92037, USA,

Tel: + I 858784 7262, Fax: + I 8587847405 ,

E-mail: mroberto@scripps.edu

Received 5 September 2013; revised 8 October 2013; accepted 24 October 2013; accepted article preview online 30 October 2013
Nociceptin/orphanin FQ (nociceptin) is a 17-amino-acid opioid-like peptide structurally related to the opioid peptide dynorphin A (Meunier, 1997; Reinscheid et al, 1995) that acts at the receptor opioid receptor-like 1 now named nociceptin receptors (NOP). Despite its structural homology with opioid peptides, nociceptin does not bind to $\mu, \delta$, and $\kappa$ opioid receptors nor do opioid peptides activate the NOP receptor. Activation of membrane NOP receptors by nociceptin results in the same sequence of intracellular events induced by opioid receptors, namely negative coupling with adenylyl cyclase, activation of inwardly rectifying $\mathrm{K}^{+}$channels, and inhibition of $\mathrm{Ca}^{2+}$ current in a pertussis toxin-sensitive manner (Ciccocioppo et al, 2000; Meunier, 1997; Reinscheid et al, 1995). However, these cellular responses to nociceptin are insensitive to naloxone (Darland et al, 1998; Henderson and McKnight, 1997), confirming that the pharmacological actions of this peptide are not mediated by the classic opioid receptors. Despite being opioid-like, nociceptin acts in the brain to produce functional antiopioid effects (for a review see Martin-Fardon et al, 2010; Ubaldi et al, 2013). NOP receptor expression 
and binding are widespread throughout the rodent and primate brain, supporting the role of the N/OFQ-NOP system in the modulation of central functions, such as sensory nociceptive processing, learning and memory, reward, mood, feeding, stress, and drug addiction (Lambert, 2008; Mogil and Pasternak, 2001; Schank et al, 2012). Nociceptin has an anxiolytic-like effect (Jenck et al, 1997), decreases ethanol drinking, and prevents relapse-like behavior in rats (Ciccocioppo et al, 2004; Kuzmin et al, 2007). Our laboratory has extensively studied the synaptic effects of nociceptin on GABAergic transmission in the CeA, where we observed a nociceptin-induced decrease in GABAergic transmission and a blockade of the ethanolinduced increase of GABA release (Roberto and Siggins, 2006b). It has been shown that nociceptin inhibits glutamate release in various preparations, due to a reduction in the excitability of the presynaptic terminals and/or a reduction in transmitter secretion (Calo et al, 2000; Neal et al, 1999). For instance, nociceptin reduced glutamatergic transmission in the rat periaqueductal gray (Vaughan et al, 1997), hippocampus (Tallent et al, 2001; Yu et al, 1997), dorsal horn of the rat spinal cord (Liebel et al, 1997; Zeilhofer et al, 2000), arcuate nucleus (Emmerson and Miller, 1999), suprachiasmatic nucleus (Gompf et al, 2005), lateral amygdala (Meis and Pape, 2001), and rat thalamic reticular nucleus (Meis et al, 2002). However, there are no studies on the action of nociceptin on glutamatergic transmission in rat CeA.

Although the majority (95\%) of CeA neurons are GABAergic, the $\mathrm{CeA}$ receives numerous glutamatergic terminals from the basolateral amygdala (BLA) (Krettek and Price, 1978; Pitkanen et al, 1995; Savander et al, 1995). Glutamate is the major excitatory neurotransmitter and its modulation by ethanol contributes to ethanol reinforcement, tolerance, and dependence (Lovinger and Roberto, 2013). Ethanol has consistent inhibitory actions on ionotropic glutamate receptors, including the AMPA and NMDA receptors (AMPARs and NMDARs) throughout the brain (Lovinger et al, 2013). We have demonstrated that in most CeA neurons from naive rats, superfusion of 5-66 mM ethanol significantly decreased evoked compound glutamatergic excitatory postsynaptic potentials or currents (EPSP/ Cs), as well as pharmacologically isolated NMDAR- and nonNMDAR-mediated EPSP/Cs (Roberto et al, 2004b). However, these ethanol effects were not associated with presynaptic actions on glutamate release in naive rats. In $\mathrm{CeA}$ slices taken from chronic ethanol-treated rats, the acute ethanolinduced depression of NMDAR-EPSP/Cs was enhanced via both pre- and postsynaptic actions (Roberto et al, 2004b).

Therefore, in this study, we used an in vitro slice preparation to assess the effects of nociceptin on both evoked and spontaneous glutamatergic transmission in the $\mathrm{CeA}$ of naive and ethanol-dependent rats and the interaction of nociceptin with acute ethanol at these synapses.

\section{MATERIALS AND METHODS}

\section{Animals and Slice Preparation}

We used adult male Wistar rats $(435.2 \pm 26 \mathrm{~g} ; n=68)$ from Charles River (Raleigh, NC). We used the standard ethanol inhalation method of The Scripps Research Institute
Alcohol Research Center to induce ethanol dependence (Rogers et al, 1979). Rats were placed into ethanol vapor chambers and intermittently exposed ( $14 \mathrm{~h}$ on, $10 \mathrm{~h}$ off) to ethanol vapors for 4 weeks. On experiment days, chronic ethanol-exposed rats were maintained in the ethanol vapor chamber until preparation of the CeA slices (under ethanolfree conditions). The blood alcohol level target range in the rats during vapor exposure was $150-200 \mathrm{mg} \%$. Naive/ control rats were exposed to air $24 \mathrm{~h}$ per day. We prepared CeA slices as detailed in the Supplementary Information and as described previously (Cruz et al, 2012; Roberto et al, 2004b; Roberto and Siggins, 2006b).

\section{Intracellular Recording of Evoked Responses}

We recorded from CeA neurons (from the medial subdivision of the (eA) with sharp micropipettes filled with $3 \mathrm{M}$ $\mathrm{KCl}$ using discontinuous current-clamp mode, as described previously (for details see the Supplementary Information and Cruz et al, 2012; Roberto et al, 2004b). We evoked EPSPs by stimulating locally within the CeA using a bipolar stimulating electrode and pharmacologically isolated the potentials using $\mathrm{GABA}_{\mathrm{A}}$ and $\mathrm{GABA}_{\mathrm{B}}$ receptor blockers (30 $\mu \mathrm{M}$ bicuculline and $1 \mu \mathrm{M}$ CGP $55845 \mathrm{~A}$, respectively). We examined paired-pulse facilitation (PPF) in each neuron using paired stimuli at 50 and $100 \mathrm{~ms}$ interstimulus interval (for details see Supplementary Information and Roberto et al, 2004b). To determine the synaptic response parameters for each cell, we performed an input-output (I-O) protocol (Cruz et al, 2012; Roberto et al, 2003, 2004a, 2010) consisting of a range of five current stimulations (typically between 50 and $250 \mathrm{nA}$ ), starting at the threshold current required to elicit an EPSP. From this threshold, the stimulus strength is increased in 3-5 steps of $30-50 \mathrm{nA}$ (rate of 1 pulse per $8 \mathrm{~s}$ ) until the voltage required to elicit the maximum amplitude is reached. To show drug effect, we normalized the three middle (omitting threshold and maximal) stimulus intensities of five equal steps as $1-3 \times$.

\section{Whole-Cell Patch-Clamp Recording of s/mEPSCs}

We visualized CeA neurons in brain slices using infrared differential interference contrast optics and a CCD camera and made whole-cell voltage-clamp recordings with a Multiclamp 700B amplifier (Molecular Devices, Sunnyvale, CA), as described previously (Cruz et al, 2012; Herman et al, 2013). Glutamatergic sEPSCs were recorded in the presence of GABA receptor blockers and mEPSCs in the presence of $1 \mu \mathrm{M}$ tetrodotoxin (TTX) (for details see Supplementary Information). All 35 cells were clamped at $-60 \mathrm{mV}$ for the duration of the recording. In all experiments, series resistance $(<10 \mathrm{M} \Omega)$ was continuously monitored with a $10 \mathrm{mV}$ hyperpolarizing pulse and experiments with $>20 \%$ change in series resistance were not included in the final analysis.

\section{Drugs}

We purchased picrotoxin and bicuculline from Sigma ( $\mathrm{St}$ Louis, MO), TTX from Biotum (Hayward, CA), CGP 55845A, DNQX, DL-AP5, [Nphe1]Nociceptin(1-13)NH2, and nociceptin from Tocris (Ellisville, MO), and ethanol from Remet (La Mirada, CA). All other chemical reagents 
were purchased from Sigma-Aldrich (St Louis, MO). DNQX and bicuculline were dissolved in DMSO (0.01\%), and CGP 55845A, DL-AP5, [Nphe1]Nociceptin(1-13)NH2, and nociceptin were dissolved in distilled water and then added to aCSF.

\section{Data Analysis and Statistics}

To analyze data acquired from intracellular and whole-cell recordings, we used Clampfit 10.2 (Molecular Devices) and MiniAnalysis 5.1 software (Synaptosoft), respectively. We used GraphPad Prism 5.0 software (GraphPad Software, San Diego, CA) and Statistica 7 Package (StatSoft, Tulsa, OK) for all statistical analysis of results. The s/mEPSC results were evaluated with cumulative probability analysis, and statistical significance was determined using the KolmogorovSmirnov, non-parametric two-sample test (Van der Kloot, 1991). The pooled data for each experimental condition were then analyzed by paired $t$-test analyses for individual means comparisons to evaluate single drug (nociceptin and [Nphe1]Nociceptin(1-13)NH2) effect within the same group (naive or ethanol-exposed rats) or within-subject one-way repeated-measures (RM) ANOVA to evaluate multiple drugs (nociceptin, nociceptin + ethanol) effects. We used $t$-test analyses to evaluate differences in individual means of evoked EPSPs between two treatments (eg, when the effect of each dose of nociceptin or the NOP receptor antagonist, [Nphe1]Nociceptin(1-13)NH2, was compared with the respective baseline values). We also used within-subject one-way RM ANOVA to compare EPSPs in the same group of cells (naive $v s$ dependent rats) after application of different drugs (nociceptin, nociceptin + ethanol). When appropriate, the Student-Newman-Keuls post hoc test was used to assess significance between treatments. To assess differences resulting from ethanol exposure (naive-control $v s$ ethanol-dependent rats) and drug interaction between groups, we used a two-way RM ANOVA. When appropriate, the Student-Newman-Keuls post hoc test was used to assess significance between treatments. We accepted statistical significance at the $P<0.05$. All averaged values are presented as mean \pm SEM. We measured the EPSP amplitudes before (control = baseline $=$ predrug), during drug application, and after (washout) drug application, and we determined the percent change in EPSP amplitude at each stimulus intensity using the equation: (value drug/value control) $\times 100$.

\section{RESULTS}

\section{Nociceptin Reduces Glutamatergic Transmission in CeA Neurons}

We recorded intracellularly with sharp pipettes from 109 CeA neurons. The mean resting membrane potential (RMP) was $-78 \pm 1.7 \mathrm{mV}$ and mean input resistance was $125 \pm$ $5.8 \mathrm{M} \Omega$.

We first generated a dose-response curve testing the effects of four concentrations of nociceptin $(100,250,500$, and $1000 \mathrm{nM}$ ) on evoked compound glutamatergic EPSPs in naive-control rat CeA. Overall ANOVA demonstrated that 15 min of nociceptin superfusion significantly $(\mathrm{F}(3,34)=$ 5.36, $P<0.001)$ decreased the mean amplitude of evoked
EPSPs. The histograms in Figure 1 express percent peak decrease in evoked EPSP amplitudes at half-max stimulus intensity obtained from the I-O relationship during nociceptin superfusion. The lowest concentration of nociceptin tested $(100 \mathrm{nM})$ did not significantly affect EPSPs (86.9 $\pm 6.5 \%$ of control; $P>0.05, n=6$ ), whereas 250, 500, and $1000 \mathrm{nM}$ nociceptin decreased EPSP amplitude to $73.8 \pm 4.6 \% \quad(P<0.001, \quad n=9), \quad 74.9 \pm 4.1 \% \quad(P<0.001$, $n=18)$, and $81.5 \pm 6.0 \% \quad(P<0.05, \quad n=5)$, respectively (Figure 1a). Because 250 and $500 \mathrm{nM}$ nociceptin induced similar and maximal inhibitions of the evoked EPSPs, we used these concentrations throughout the rest of the study, unless specified otherwise. We found that nociceptin, at all the concentrations applied, did not significantly alter neuronal RMPs and input resistance. Current-voltage $(I-V)$ relationship analysis also showed that $500 \mathrm{nM}$ nociceptin had no significant effect on membrane potential, conductance (Figure $1 \mathrm{~b}$ and Supplementary Figure $1 \mathrm{~A}$ and $\mathrm{B})$, or the number of action potentials upon depolarization across the CeA cell types (Supplementary Figure 1C and D).

Nociceptin could alter pre- and/or postsynaptic sites to decrease evoked EPSP amplitudes. To determine where nociceptin acts to decrease glutamate transmission, we examined PPF, a phenomenon whereby a secondary synaptic response is influenced by a preceding primary stimulus of equal intensity (Andreasen and Hablitz, 1994; Manabe et al, 1993). Generally, changes in the PPF ratio (second EPSP/first EPSP) are inversely related to transmitter release such that a reduction of the PPF ratio is associated with an increased probability of transmitter release (Roberto et al, 2004b). We found that 250 and $500 \mathrm{nM}$ nociceptin significantly $(P<0.05$ by paired $t$-test; Figure $1 c$ and $d$ ) increased the PPF ratios of EPSPs in CeA neurons, suggesting decreased evoked glutamate release. Specifically, $250 \mathrm{nM}$ nociceptin significantly $(P<0.05)$ increased the $50 \mathrm{~ms} P P F$ ratio from $0.99 \pm 0.1$ to $1.31 \pm 0.15$, and $500 \mathrm{nM}$ nociceptin significantly $(P<0.05)$ increased 50 and $100 \mathrm{~ms}$ PPF ratios from $1.32 \pm 0.09$ to $1.94 \pm 0.19$ and from $1.23 \pm 0.09$ to $1.45 \pm 0.07$, respectively (Figure 1c). The lowest and the highest nociceptin concentrations used did not alter the PPF ratios (Figure 1c).

\section{Nociceptin Blocks the Ethanol-Induced Decrease of Glutamatergic Transmission in CeA Neurons}

Here, we recapitulated the finding that ethanol significantly decreases evoked glutamatergic responses in $11 \mathrm{CeA}$ neurons (Figure 2), as reported previously (Roberto et al, 2004b). Ethanol (44 mM, a dose producing maximal effects) significantly $(P<0.05$ by paired $t$-test $)$ decreased the mean amplitude of evoked EPSPs to $81 \pm 3 \%$ of control over the three stimulus intensities (Figure 2a), with recovery on washout. Ethanol did not alter the PPF ratios of EPSPs (Figure $2 \mathrm{~b}$ ) and the $I-V$ relationships (Figure $2 \mathrm{c}$ ).

We previously reported that nociceptin strongly blocked the ethanol-induced increase in GABA release at $\mathrm{CeA}$ synapses (Roberto and Siggins, 2006b), so here we investigated whether CeA NOP activation by nociceptin alters the effects of ethanol on glutamatergic transmission. To test the influence of NOP activation on the ethanolinduced decrease of EPSPs, we first superfused a maximal concentration of nociceptin $(500 \mathrm{nM})$ for $12-15 \mathrm{~min}$ and 
a

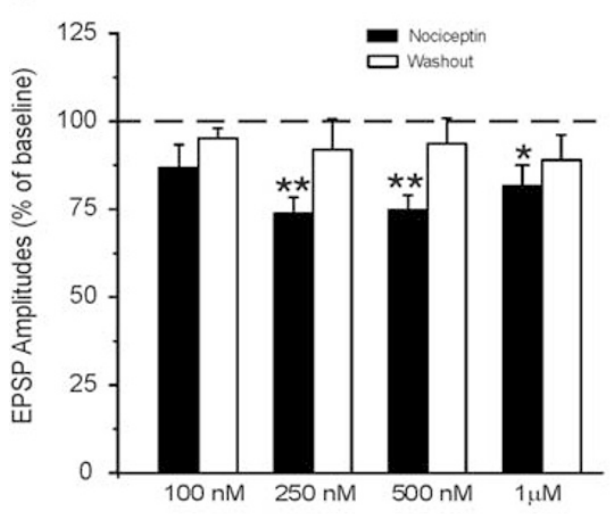<smiles>C1CC1</smiles>

Control

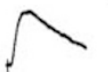

Control

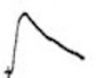

control
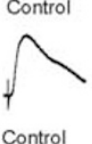

control

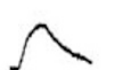

$250 \mathrm{nM} \mathrm{Noc}$

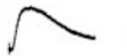

500 M

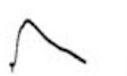

$1 \mu \mathrm{M} \mathrm{NoC}$

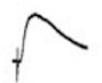

$100 \mathrm{nM}$ Noc

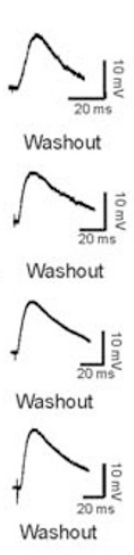

b

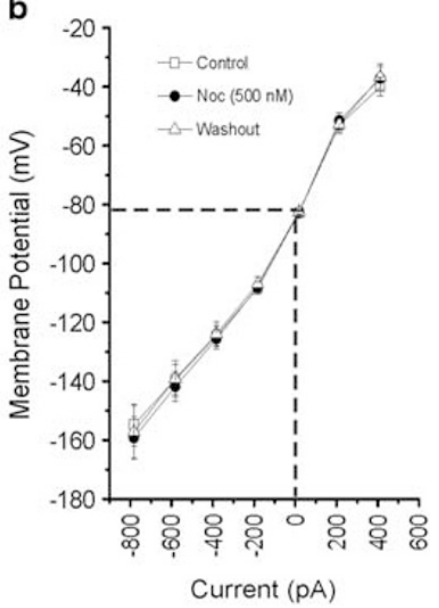

c

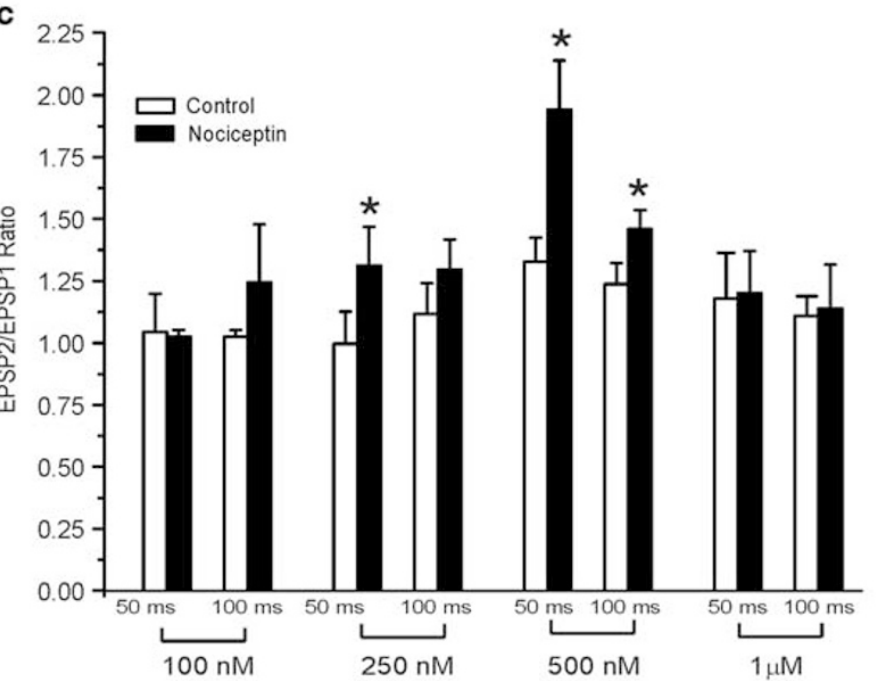

d

PPF $50 \mathrm{~ms} \quad$ PPF $100 \mathrm{~ms}$<smiles>CCCCCC</smiles>
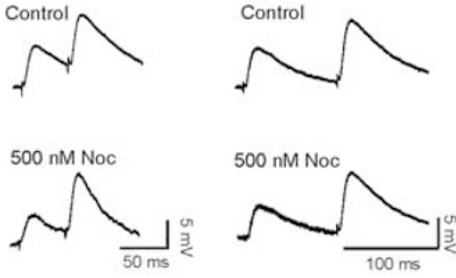

Figure I Nociceptin decreases evoked excitatory postsynaptic potential (EPSP) amplitudes in the central nucleus of the amygdala (CeA) of naive rats. (a, left panel) Histograms representing percent peak decrease in evoked (at half-max stimulus intensity) EPSP amplitudes during superfusion of different concentrations (100, 250,500, and I000 nM) of nociceptin and washout. (Right panel) Representative recordings of evoked EPSPs in CeA neurons from naive rats recorded before, during, and after washout from nociceptin application. Statistical significance of nociceptin's effect compared with baseline by paired $t$-test is indicated by $* P<0.05$ and $* * P<0.00 I$. (b) $I-V$ curve showing that superfusion of nociceptin $(500$ nM) does not change the RMP in rat CeA neurons $(n=15)$. (c) Nociceptin $(250$ and $500 \mathrm{nM}$ ) significantly increases the paired-pulse facilitation (PPF) ratio of evoked EPSPs using 50 and $100 \mathrm{~ms}$ interstimulus intervals. Significance of the effect of nociceptin compared with baseline by paired $t$-test $(* P<0.05)$. (d) Representative recordings of PPF at both 50 (left traces) and 100 (right traces) $\mathrm{ms}$ in a CeA neuron from a naive rat before and during superfusion of $500 \mathrm{nM}$ nociceptin.

then added $44 \mathrm{mM}$ ethanol in the continued presence of nociceptin (Figure $2 \mathrm{~d}$ and e). The time course of Figure $2 \mathrm{~d}$ expresses the percent of control using the middle stimulus intensity obtained from the I-O relationship of Figure 2e. We observed the effects of nociceptin within 5-7 min of superfusion (Figure 2d). One-way RM ANOVA showed significant drug effect $(\mathrm{F}(2,23)=23.90, P<0.001)$. Specifically, nociceptin $(500 \mathrm{nM})$ significantly $(P<0.05$ by Newman-Keuls test) decreased EPSP amplitudes (averaged across all stimulus strengths) to $77.2 \pm 8 \%$ of control, and subsequent ethanol coapplication did not significantly alter the EPSPs (70.1 $\pm 9 \%$ of control; $P>0.05$; Figure 2e). The EPSP inhibition was partially reversible upon $30 \mathrm{~min}$ drug washout. In another two neurons, ethanol further decreased the amplitude of the EPSP, indicating that nociceptin did not block the ethanol-induced depression of EPSPs. Nociceptin also significantly $(P<0.05$ by paired $t$-test $)$ increased 50 and $100 \mathrm{~ms}$ PPF ratios from $1.25 \pm 0.2$ to $1.85 \pm$ 0.2 and from $1.25 \pm 0.1$ to $1.55 \pm 0.2$, respectively, whereas the addition of ethanol did not further alter these PPF ratios ( $50 \mathrm{~ms}, 1.67 \pm 0.2 ; 100 \mathrm{~ms}, 1.45 \pm 0.2$ ). Similar to the $500 \mathrm{nM}$ nociceptin concentration, one-way RM ANOVA showed significant drug effect of $250 \mathrm{nM}$ nociceptin $(\mathrm{F}(2,14)$ $=27.31, \quad P<0.001)$, with a significant $(P<0.05$ by Newman-Keuls test) decrease in EPSPs to $74.8 \pm 6 \%$ of baseline and no further effect from ethanol coapplication ( $73.7 \pm 8 \%$ of baseline; $n=5$ ).

In a second set of experiments, we inverted the order of drug applications. Overall ANOVA showed a significant drug effect $(F(2,34)=30.18, P<0.001)$, whereby ethanol significantly $(P<0.05$ by Newman-Keuls test $)$ decreased EPSPs to $84.0 \pm 2.7 \%$ of control (averaged across all stimulus strengths; $n=6$; Figure $2 \mathrm{f}$ ) and nociceptin coapplication had no further effect $(79.4 \pm 4.8 \%$ of control). Neither ethanol nor nociceptin altered the 50 and $100 \mathrm{~ms}$ PPF ratios (control: $1.27 \pm 0.18$ and $1.31 \pm 0.21$; ethanol: $1.29 \pm 0.09$ and $1.53 \pm 0.22$; nociceptin: $1.22 \pm 0.17$ and $1.45 \pm 0.15 ; n=6)$. 

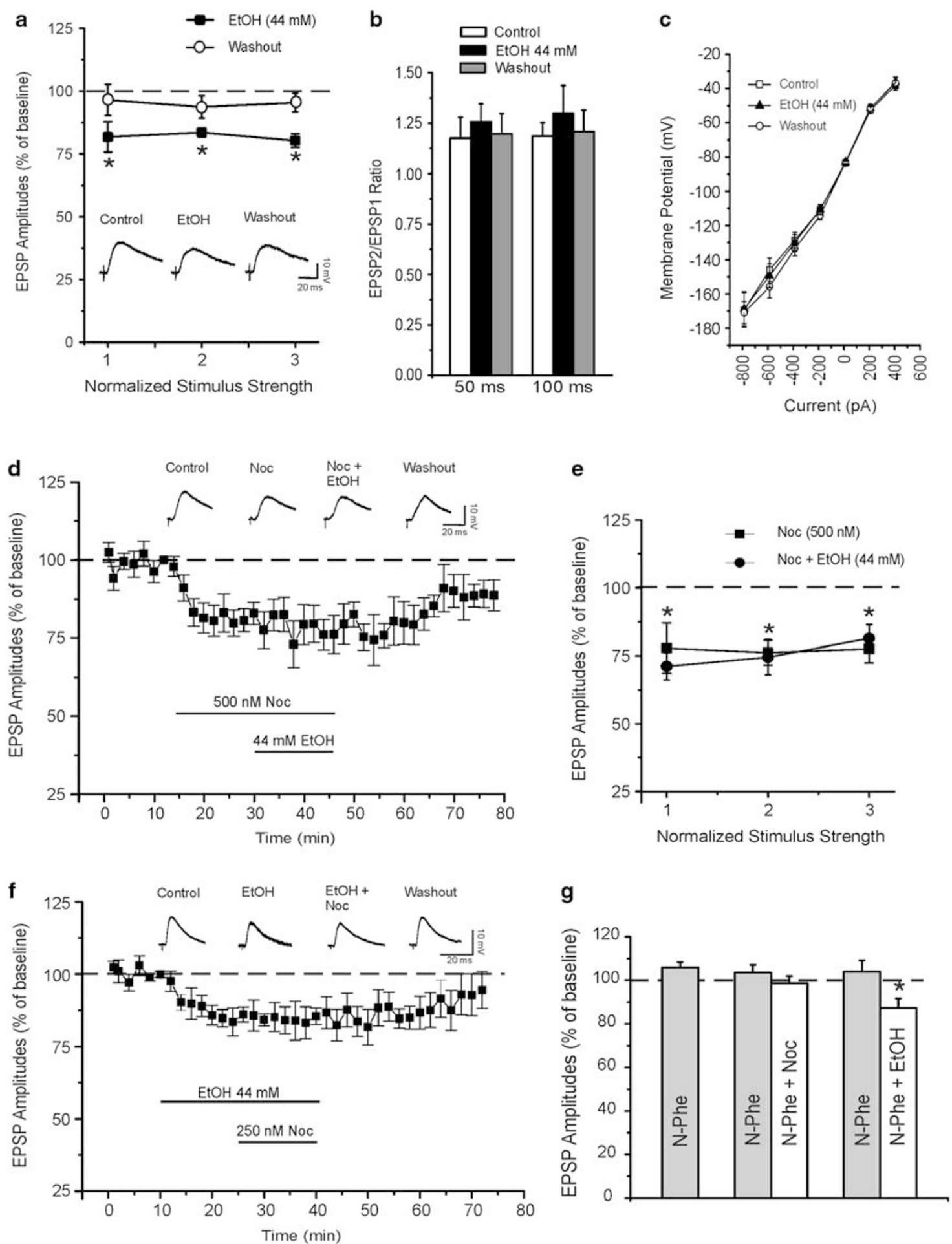

Figure 2 Ethanol decreases evoked excitatory postsynaptic potential (EPSP) amplitude in central nucleus of the amygdala (CeA) neurons of naive rats and nociceptin blocks this effect. (a) Ethanol $(44 \mathrm{mM})$ significantly $(P<0.05 ; n=1$ I by paired $t$-test) and reversibly decreases EPSP amplitudes to $\sim 80 \%$ of control. (Inset) Representative EPSP recordings in a CeA neuron during baseline, ethanol, and washout. (b) Ethanol had no effect on 50 or $100 \mathrm{~ms}$ paired-pulse facilitation (PPF) ratios of EPSPs. (c) I-V curve showing that superfusion of ethanol $(44 \mathrm{mM})$ does not change the RMP in rat CeA neurons ( $n=1 \mathrm{I}$ ). (d) Time course of changes in evoked EPSP amplitude induced by nociceptin $(500 \mathrm{nM})$, concurrent application of ethanol, and washout $(n=8)$. (Inset) Representative CeA EPSP recordings during baseline, nociceptin, nociceptin + ethanol, and washout. (e) Nociceptin significantly decreases the mean amplitudes of evoked EPSPs over the middle three stimulus strength intensities tested. *Significance for $P<0.05$ of nociceptin effect compared with baseline. Subsequent application of ethanol ( $44 \mathrm{mM}$ ) did not alter the EPSP amplitudes $(n=8)$. ( $f$ ) Time course of changes in EPSP amplitude evoked by ethanol, concurrent application of nociceptin (250 $n M)$, and washout $(n=6)$. (Inset) Representative CeA EPSP recordings during baseline, ethanol, ethanol + nociceptin, and washout. (g) Application of a NOP antagonist ([Nphe I]nociceptin $(\mathrm{I}-13) \mathrm{NH} 2)(\mathrm{N}-\mathrm{Phe}, \mathrm{I} \mu \mathrm{M})$ does not alter the basal-evoked EPSP amplitudes (stimulus intensity equal to half-maximal EPSP amplitude) in I I CeA neurons of control rats (left histogram). The NOP antagonist prevents the nociceptin-induced decrease of EPSP amplitudes ( $n=4$, middle histograms), but does not prevent the ethanol-induced decrease of EPSP amplitudes ( $n=5$, right histograms). *Significance $P<0.05$ of ethanol and NOP antagonist effects. 
To determine whether NOP receptors regulate baselineevoked glutamatergic transmission, and to test their involvement in ethanol effects in the CeA, we tested [Nphe1]Nociceptin(1-13)NH2, a putative selective NOP receptor antagonist (Cruz et al, 2012; Roberto and Siggins, 2006b). [Nphe1]Nociceptin(1-13)NH2 $(1 \mu \mathrm{M})$ did not alter evoked EPSPs $(106.7 \pm 2.4 \%$ of control at half-maximal stimulus intensity; $n=11$; by paired $t$-test; Figure $2 \mathrm{~g}$ ). To verify that nociceptin decreased EPSPs in the CeA by activating NOPs, we applied nociceptin $(250 \mathrm{nM})$ in the presence of the antagonist and found that nociceptin no longer decreased the EPSP amplitude (Figure 2g). We also tested whether NOP blockade affects ethanol-induced decreases in EPSPs. One-way RM ANOVA showed a significant drug effect $(\mathrm{F}(2,8)=29.86, P<0.001)$. Application of the NOP antagonist did not alter ethanol's ability to significantly $(P<0.05$ by Newman-Keuls test $)$ decrease EPSPs (from $104.0 \pm 5.2 \%$ to $87.2 \pm 4.3 \%$ of control at halfmaximal stimulus intensity; $n=5$; Figure $2 \mathrm{~g}$ ), ruling out mediation of the ethanol effects by the NOP receptors.

\section{Chronic Ethanol Exposure Does not Alter Nociceptin Signaling in CeA Neurons}

Next, we determined whether our chronic ethanol treatment that induces ethanol dependence could alter the nociceptin/ NOP system and its interaction with acute ethanol in the CeA. As reported previously, we did not observe a significant difference between the baseline compound EPSP I-O curves in slices from naive and ethanol-dependent animals (recorded at early withdrawal 2-8 $\mathrm{h}$ after ethanol exposure; Figure 3a). We then tested two maximal concentrations of nociceptin (250 and $500 \mathrm{nM})$ and overall ANOVA showed a significant nociceptin effect $(\mathrm{F}(1,17)$ $=21.43 ; P<0.001)$ and $(\mathrm{F}(1,25)=32.86 ; P<0.001)$ for both concentrations in ethanol-dependent rats, but no chronic ethanol treatment effects (compared with 11 and 18 cells from naive rats). Similar to naive rats, 250 and $500 \mathrm{nM}$ nociceptin significantly $(P<0.05)$ decreased EPSP amplitudes to $77.3 \pm 2.8 \%(n=8)$ and $84.2 \pm 2.6 \% \quad(n=9)$ of control (averaged across all stimulus strengths; Figure $3 \mathrm{~b}$ ) in the ethanol-dependent rats, suggesting that ethanol dependence does not alter the nociceptin-induced decrease in glutamatergic transmission in the CeA. We found that $250 \mathrm{nM}$ nociceptin significantly $(P<0.05$ by paired $t$-test $)$ increased the $50 \mathrm{~ms} P P F$ ratio from $1.11 \pm 0.15$ to $1.76 \pm 0.21$, without altering the $100 \mathrm{~ms} \operatorname{PPF}(1.46 \pm 0.15$ to $2.02 \pm 0.36)$ and $500 \mathrm{nM}$ nociceptin significantly $(P<0.05$ by paired $t$-test) increased the 50 and $100 \mathrm{~ms}$ PPF ratios from $0.98 \pm 0.09$ to $1.22 \pm 0.1$ and from $0.96 \pm 0.07$ to $1.16 \pm 0.09$, respectively (Figure 3c). Although the magnitude of the $500 \mathrm{nM}$ nociceptin-induced increase in 50 and $100 \mathrm{~ms}$ PPF ratios showed a tendency to be smaller in ethanoldependent rats (Figure 3c) compared with naive rats (Figure 1c), overall two-way RM ANOVA did not reveal any significance difference $((\mathrm{F}(1,21)=2.39, P=0.1363)$ and $(\mathrm{F}(1,21)=0.84, \quad P=0.3691)$, respectively). To determine whether NOPs regulate baseline-evoked glutamatergic transmission in CeA neurons of ethanol-dependent rats, we tested $1 \mu \mathrm{M}$ [Nphe1]Nociceptin(1-13)NH2. Overall ANOVA showed a significant drug effect $(\mathrm{F}(1,16)=28.79$; $P<0.0001)$. Specifically, the NOP antagonist significantly
$(P<0.001)$ increased the EPSP amplitude to $114.5 \pm 1.9 \%$ of control (at half-maximal stimulus intensity; $n=7$; Figure 3d), suggesting a significant tonic activation of nociceptin/NOP signaling in the CeA of ethanol-dependent rats. The NOP antagonist also significantly $(P<0.05$ by paired $t$-test) decreased 50 and $100 \mathrm{~ms}$ PPF ratios from $1.28 \pm 0.2$ to $0.91 \pm 0.09$ and from $1.34 \pm 0.1$ to $1.00 \pm 0.03$, respectively.

In the CeA of ethanol-dependent rats, overall ANOVA $(\mathrm{F}(1,18)=89.45 ; P<0.0001)$ revealed that $44 \mathrm{mM}$ ethanol significantly $(P<0.001)$ decreased the evoked compound EPSPs (Figure $3 \mathrm{e}$ ) to $83.7 \pm 3.2$ of control (averaged across all stimulus strengths; $n=9$ ), similar to the ethanol effect in naive rats (compare Figure 2a). Although acute ethanol had no effect on PPF ratios in naive rats (Figure 2b), it significantly $(P<0.05$ by paired $t$-test) decreased the 50 and $100 \mathrm{~ms}$ PPF ratios by $15-20 \%$ in ethanol-dependent rats (Figure 3f and Roberto et al, 2004b).

Thus, we examined the interaction of nociceptin and ethanol in the CeA of ethanol-dependent rats. One-way RM ANOVA showed significant drug effect $(F(2,20)=32.40$, $P<0.001)$; specifically nociceptin $(500 \mathrm{nM})$ significantly $(P<0.05$ by Newman-Keuls test $)$ decreased evoked EPSPs and subsequent application of $44 \mathrm{mM}$ ethanol did not further alter EPSP amplitude (it remained at about $80 \%$ of control; $n=7$; Figure $4 \mathrm{a}$ and $\mathrm{b}$ ). These results were similar to those obtained from naive rats (compare Figure $2 \mathrm{~d}$ and e). Nociceptin significantly $(P<0.05)$ increased 50 and $100 \mathrm{~ms}$ PPF ratios (baseline: $0.99 \pm 0.08$ and $0.97 \pm 0.09$; nociceptin: $1.3 \pm 0.1$ and $1.21 \pm 0.1$ ) and ethanol coapplication did not further alter these PPF ratios (ethanol: $1.26 \pm 0.13$ and $1.18 \pm 0.09$; Figure $4 \mathrm{c}$ ). Thus, in ethanoldependent rats, the nociceptin-induced inhibition of glutamatergic transmission completely pre-empted the effect of ethanol.

\section{Nociceptin Decreases Spontaneous Glutamatergic Transmission in the CeA of Naive and Ethanol-Dependent rats}

To further pursue the site of nociceptin action, we used whole-cell voltage-clamp recording to study sEPSCs and then mEPSCs in CeA neurons of naive rats. Generally, a change in s/mEPSC frequency indicates an altered probability of transmitter release, and a change in s/mEPSC amplitude reflects alterations in the sensitivity of postsynaptic glutamate receptors (De Koninck and Mody, 1994; Otis et al, 1994). Interestingly, the baseline frequency $(0.98 \pm 0.16 \mathrm{~Hz}, n=17)$ and amplitudes (15.23 $\pm 0.95 \mathrm{pA}$, $n=17)$ of sEPSCs were not significantly $(P>0.05$, by unpaired $t$-test) different from the baseline frequency $(1.13 \pm 0.18 \mathrm{~Hz}, \quad n=16)$ and amplitude (13.17 $\pm 0.82 \mathrm{pA}$, $n=16)$ of mEPSCs. In addition, $250 \mathrm{nM}$ nociceptin significantly $(P<0.05$ by paired $t$-test, $n=5)$ decreased sEPSC frequency to $73.7 \pm 5.4 \%$ of control, and decreased $(P<0.05)$ sEPSC amplitude to $90.9 \pm 2.2 \%$ of control (Figure $5 \mathrm{a}$ and $\mathrm{b}$ ), suggesting decreased presynaptic glutamate release and postsynaptic alterations. The rise time (control: $2.53 \pm 0.3 \mathrm{~ms}$; nociceptin: $2.46 \pm 0.3 \mathrm{~ms}$ ) and decay time (control: $5.4 \pm 1.4 \mathrm{~ms}$; nociceptin: $5.3 \pm 1.6 \mathrm{~ms}$ ) of sEPSCs were unaffected by nociceptin (Figure 5b). Similarly, nociceptin significantly decreased mEPSC frequency 


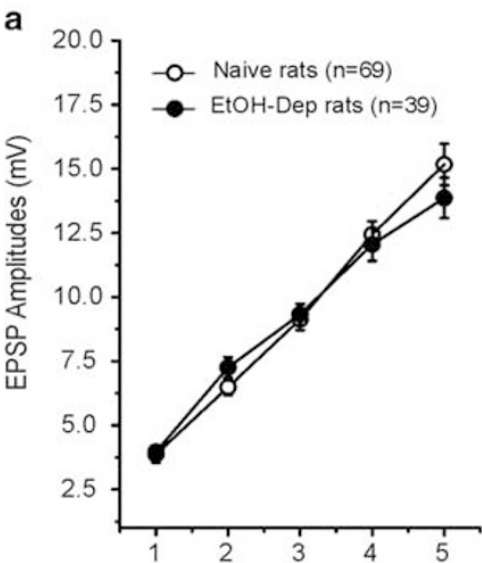

Normalized Stimulus Strength

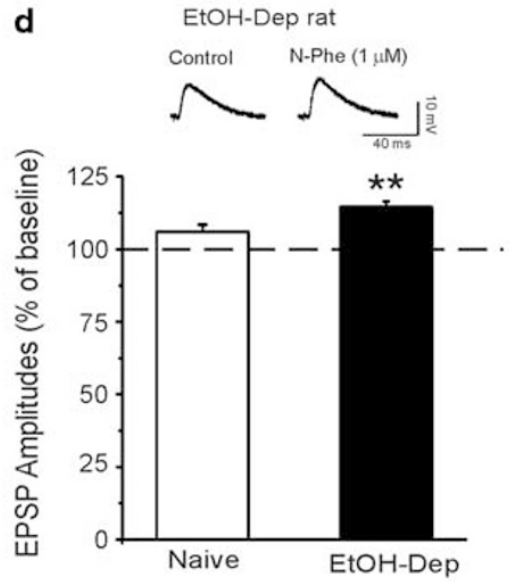

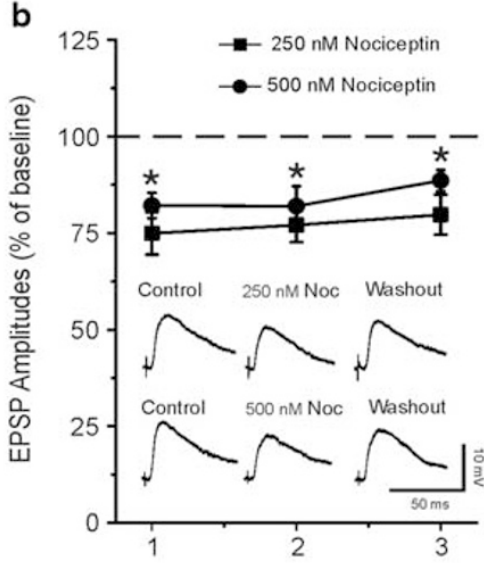
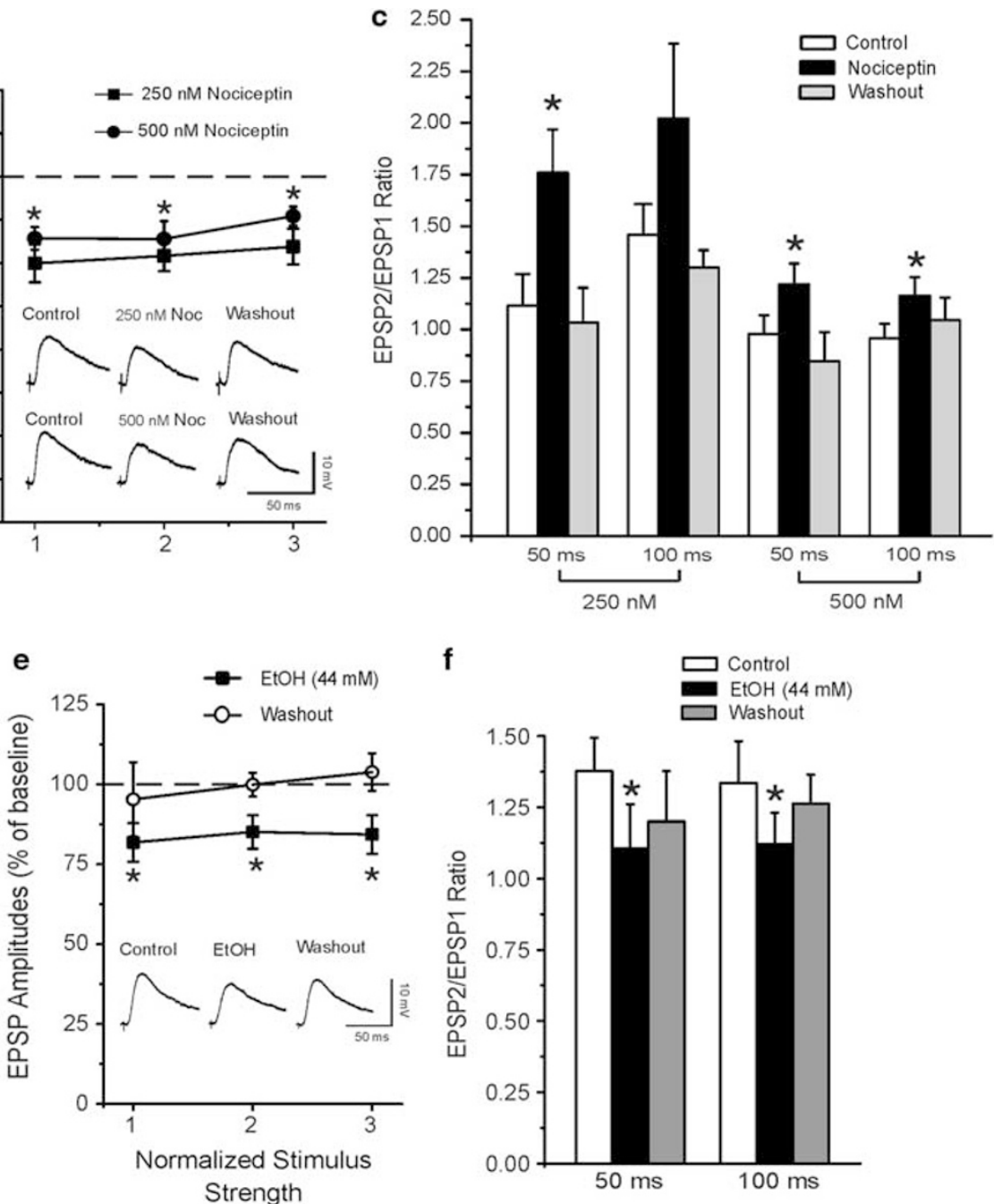

Figure 3 The effects of nociceptin on evoked EPSPs are unchanged in ethanol-dependent rats. (a) Central nucleus of the amygdala (CeA) baseline compound glutamatergic transmission is equivalent in ethanol-dependent rats compared with control naive rats. Input/output curves of mean evoked EPSP amplitudes. Note that the EPSPs are superimposable in the two groups using five equivalent stimulus intensities. (b) In the CeA of ethanol-dependent rats, both 250 and $500 \mathrm{nM}$ nociceptin significantly decreased the mean amplitudes of evoked EPSP over the middle three stimulus strength intensities tested. * Significance of the nociceptin effect compared with baseline for $P<0.05$. (Inset) Representative evoked CeA EPSPs from ethanol-dependent rats during the control, nociceptin application, and washout. (c) Nociceptin (250 and $500 \mathrm{nM}$ ) significantly increased the paired-pulse facilitation (PPF) ratio of evoked EPSPs using 50 and 100 ms interstimulus intervals. *Significance of nociceptin compared with baseline for $P<0.05$ by paired t-test. (d) Application of the NOP antagonist ([Nphel]nociceptin $(|-| 3) \mathrm{NH}$ 2) (I $\mu \mathrm{M}$ ) significantly increases basal-evoked EPSP amplitudes (stimulus intensity equal to half-maximal EPSP amplitude) in seven CeA neurons of ethanol-dependent rats. ** Significance for $P<0.00$ I of NOP antagonist compared with baseline. (e) Ethanol (44 mM) significantly $(P<0.05 ; n=9)$ and reversibly decreases EPSP amplitudes to $\sim 80 \%$ of control over the stimulus intensities in CeA of ethanol-dependent rats. (Inset) Representative EPSP recordings in a CeA neuron during baseline, ethanol (44 mM), and washout. ( $f$ ) Ethanol significantly decreases the 50 and $100 \mathrm{~ms}$ PPF ratio of EPSPs. *Significance for $P<0.05$.

to $80.5 \pm 7.2 \%$ of control $(P<0.05, n=7$; Figure $5 \mathrm{a}$ and $\mathrm{b})$, suggesting nociceptin decreased presynaptic vesicular glutamate release (action potential-independent release). However, nociceptin did not alter mEPSC amplitude (93.25 $\pm 3.7 \%$ of control; Figure $5 \mathrm{a}$ and $\mathrm{b}$ ), rise time (control: $2.49 \pm 0.4 \mathrm{~ms}$; nociceptin: $2.52 \pm 0.3 \mathrm{~ms}$ ) and decay time (control: $5.8 \pm 2.0 \mathrm{~ms}$; nociceptin: $5.9 \pm 1.7 \mathrm{~ms}$; Figure $5 \mathrm{~b}$ ).

To assess whether NOPs regulate baseline spontaneous glutamatergic transmission, we also tested the effect of the receptor antagonist. Application of [Nphe1]Nociceptin $(1-13) \mathrm{NH} 2$ increased significantly $(P<0.05)$, and to a similar extent, both sEPSC and mEPSC frequency $(133.4 \pm 9.2 \%$ and $118.7 \pm 6.2 \%$ of control; $n=6$ and 5 , respectively) without altering amplitude or rise and decay times; Figure $5 \mathrm{c}$ and d). Taken together, these results indicate that nociceptin/NOP may tonically regulate basal spontaneous CeA glutamatergic activity.

Although we did not find significant differences in the nociceptin effects on evoked EPSPs in CeA of ethanoldependent rats, we performed whole-cell voltage-clamp recordings in CeA neurons of ethanol-dependent rats. Nociceptin $(250 \mathrm{nM})$ significantly $(P<0.05, n=5)$ decreases sEPSCs frequency to $77.0 \pm 6.2 \%$ of control similar to naive rats $(73.7 \pm 5.4 \%)$. Nociceptin did not alter sEPSC amplitude ( $97.9 \pm 6.7 \%$ of control) or kinetics (Figure 5e). Similar to naive rats (Figure 5d), [Nphe1]Nociceptin(1-13)NH2 increased $(P<0.05)$ sEPSC frequency $(137.0 \pm 12.3 \%$ of control; $n=7)$ in ethanol-dependent rats, without altering 

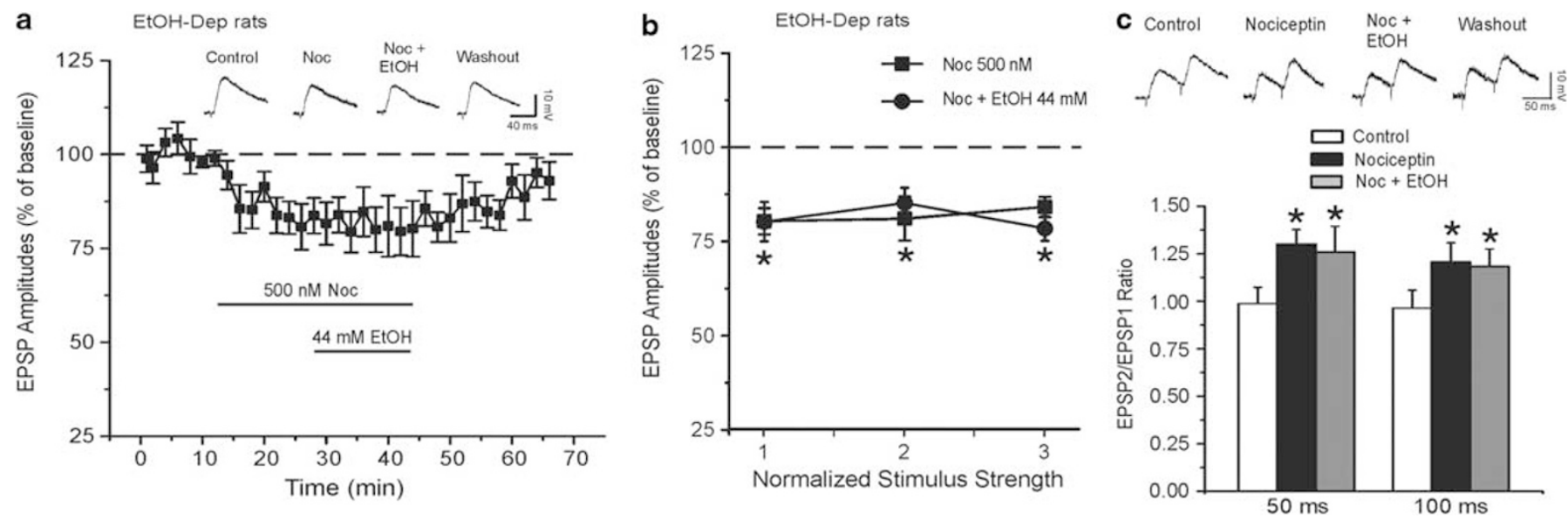

Figure 4 Nociceptin prevents the ethanol-induced decrease in evoked EPSPs in ethanol-dependent rats. (a) Time course of changes in evoked EPSP amplitude induced by nociceptin $(500 \mathrm{nM})$, concurrent application of ethanol, and washout in seven central nucleus of the amygdala (CeA) neurons of ethanol-dependent rats. (Inset) Representative CeA EPSP recordings during baseline, nociceptin, nociceptin + ethanol, and washout. (b) Nociceptin $(500 \mathrm{nM})$ significantly decreases the mean amplitudes of evoked EPSPs compared with baseline over the middle three stimulus strength intensities tested (*significance for $P<0.05$ ). Subsequent application of $44 \mathrm{mM}$ ethanol did not alter the EPSPs $(n=7)$. (c, Inset) Representative recordings of paired-pulse facilitation (PPF) at $50 \mathrm{~ms}$ in a CeA neuron from an ethanol-dependent rat during baseline, nociceptin, nociceptin + ethanol, and washout. In ethanoldependent rats, $500 \mathrm{nM}$ nociceptin significantly increases the 50 and $100 \mathrm{~ms}$ PPF ratios of evoked CeA EPSPs (*significance at $P<0.05$ ). Ethanol in the presence of nociceptin does not alter these PPF ratios.

amplitude or rise and decay times (Figure 5e), suggesting that ethanol dependence does not alter basal nociceptin signaling at the glutamatergic CeA synapses.

\section{DISCUSSION}

To our knowledge, this is the first electrophysiological study on the interaction between nociceptin and ethanol on CeA glutamatergic transmission and the influence of ethanol dependence on this interaction. In brief, we demonstrate that nociceptin decreases evoked glutamatergic responses and blocks the acute ethanol-induced inhibition of these synapses in naive and ethanol-dependent animals. Nociceptin also decreases glutamatergic transmission mainly via inhibiting spontaneous and vesicular release of glutamate in the CeA.

Nociceptin and its receptors represent a neuropeptide system bearing structural and functional analogies with classical opioid systems, but with a unique pharmacological profile (Calo et al, 2000) and a critical role in drug addiction and stress-related behaviors (Lambert, 2008; Mogil and Pasternak, 2001; Schank et al, 2012). Several studies have demonstrated that NOP activation blunts the reinforcing and motivational effects of alcohol across a range of behavioral measures (Ciccocioppo et al, 2000, 2003, 2004; Kuzmin et al, 2003; Martin-Fardon et al, 2000, 2010), suggesting that selective NOP agonists may represent a promising strategy to treat alcoholism. Interestingly, nonpeptidergic, orally available, and brain-penetrant NOP agonists may soon be ready for clinical evaluation (Schank et al, 2012). Our laboratory has extensively studied the effects of nociceptin and ethanol on CeA GABAergic transmission. Given the possible clinical implications of this neuropeptide with alcohol-related behaviors, we wanted to assess the interaction between nociceptin and ethanol at $\mathrm{CeA}$ glutamatergic synapses as well. Nociceptin decreases glutamate release in many brain regions (Emmerson and Miller, 1999; Meis et al, 2002; Meis and Pape, 2001; Vaughan et al, 1997). Similarly, here we found that nociceptin decreases both evoked and spontaneous glutamatergic transmission via both pre- and postsynaptic mechanisms in CeA neurons of naive and ethanol-dependent rats. We found that nociceptin significantly decreased the evoked EPSP amplitudes and increased the PPF ratios of EPSPs, suggesting a presynaptic site of action. Nociceptin also reduced both the frequency and amplitude of sEPSCs, suggesting that the peptide inhibits action-potential-dependent glutamate release and postsynaptic functions. Furthermore, nociceptin decreased the frequency, but not the amplitude, of action potential-independent mEPSCs, suggesting that nociceptin acts at NOPs located at or near the presynaptic terminal, but does not modulate postsynaptic functions. Possible mechanisms of altered transmitter release include $\mathrm{Ca}^{2+}$ channels inhibition within the nerve terminal and/or direct modulation of the release apparatus (Miller, 1998). As mEPSCs are usually thought to result from the spontaneous exocytosis of transmitter-containing vesicles in the absence of $\mathrm{Ca}^{2+}$ influx (Miller, 1998; Yu and Shinnick-Gallagher, 1998), our observation of quantitatively equivalent inhibition induced by the same nociceptin concentration of sEPSCs (73.7\%), mEPSCs (80\%), and evoked EPSCs (73.8\%) argues in favor of mechanisms operating downstream of $\mathrm{Ca}^{2+}$ entry (Wu and Saggau, 1994, 1997). Thus, in the CeA, like in the lateral amygdala (Meis and Pape, 2001), hippocampus (Tallent et al, 2001), and thalamus (Meis and Pape, 2001), nociceptin inhibition of glutamate release is likely to involve $\mathrm{Ca}^{2+}$ entryindependent mechanisms (Meis and Pape, 2001). Future studies into the cellular mechanism by which NOPs, which are $\mathrm{Gi} / \mathrm{Go}$-coupled receptors, mediate this presynaptic inhibition need to be performed. For instance, as these receptors can inhibit adenylyl cyclase, which decreases synaptic release, this could be a common mechanism (Tallent, 2008). In summary, it seems feasible to conclude that the effects of nociceptin on evoked and sEPSP/Cs reflect predominantly presynaptic effects, although some 


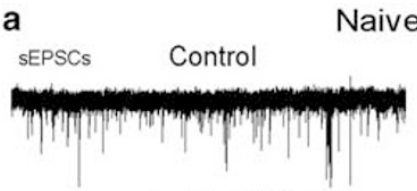

nociceptin (250 nM)
Naive rats

\author{
mEPSCs Control
}

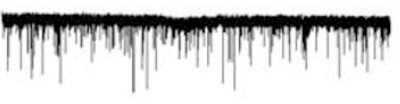

nociceptin (250 nM)
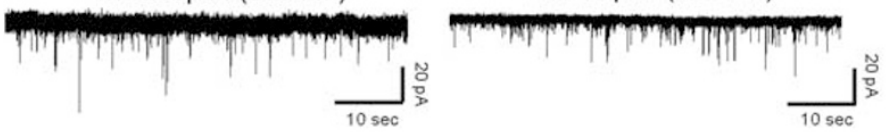

C

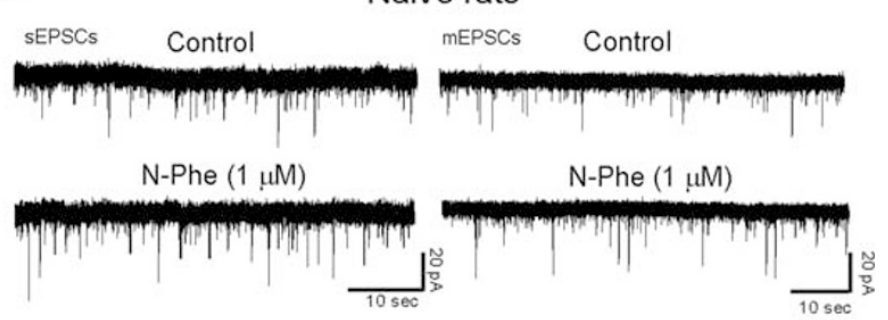

b

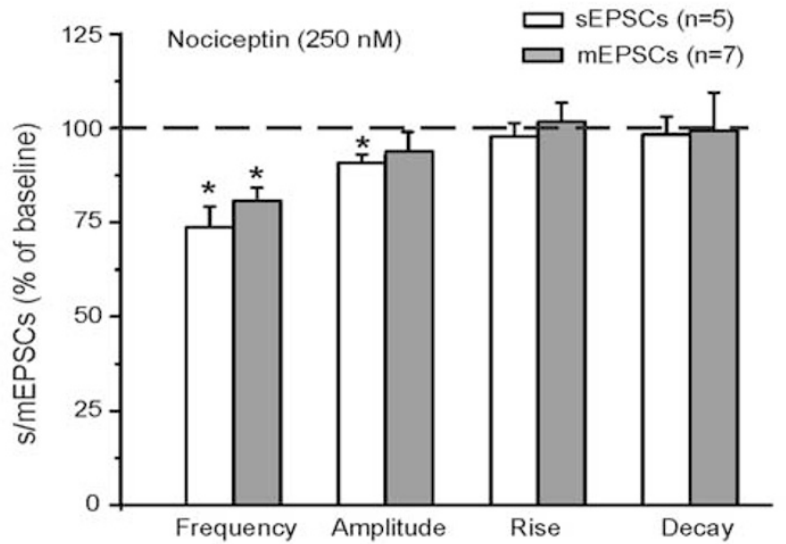

d

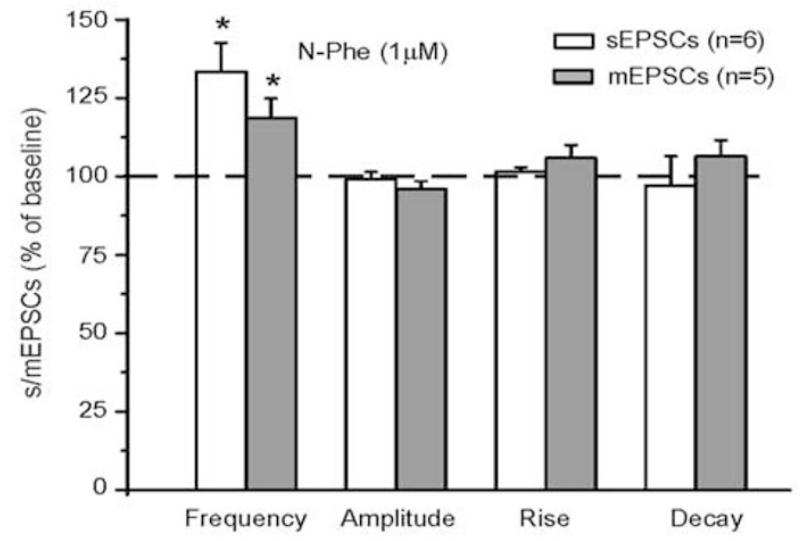

e EtOH-dependent rats

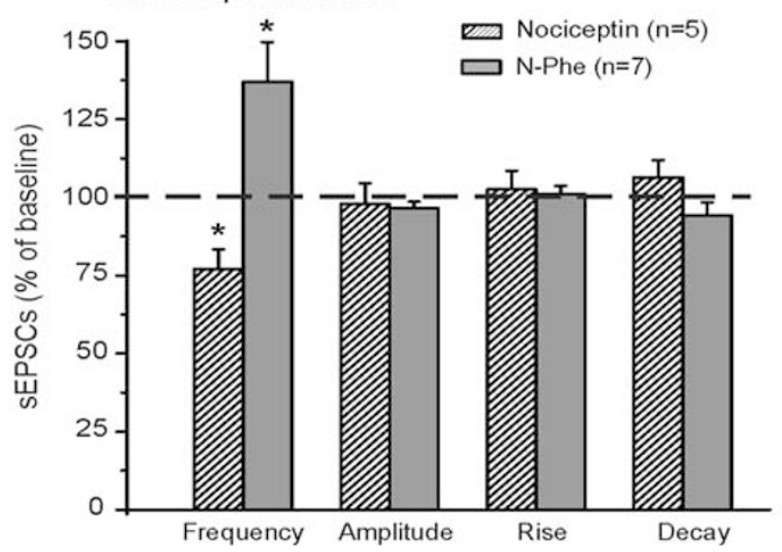

Figure 5 Nociceptin decreases spontaneous glutamatergic transmission mainly via decrease in glutamate release. (a) Representative spontaneous EPSCs (sEPSCs) and miniature EPSCs (mEPSCs) recordings in rat central nucleus of the amygdala (CeA) neurons before and during $250 \mathrm{nM}$ nociceptin application. (b) Mean \pm SEM frequency, amplitude, rise, and decay time of sEPSCs and mEPSCs for CeA neurons from control-naive rats. Nociceptin significantly decreased the sEPSC and mEPSC frequencies indicating presynaptic inhibition of both spontaneous and vesicular release of glutamate in CeA. *Significance of nociceptin effect compared with baseline by paired $t$-test for $P<0.05$. Nociceptin also significantly decreased the sEPSC amplitude (*significance at $P<0.05)$, suggesting also postsynaptic effects. (c) Representative sEPSC and mEPSC recordings in rat CeA neurons before and during I $\mu \mathrm{M}[\mathrm{Nphe}$ l]nociceptin(I-I3)NH2 in CeA neurons of control rats. (d) Mean \pm SEM frequency, amplitude, rise, and decay time of sEPSCs and mEPSCs for CeA neurons from control-naive rats. The NOP antagonist significantly increased the mean sEPSC and mEPSC frequencies (*significance at $P<0.05$ ), indicating presynaptic enhancement of both spontaneous and vesicular release of basal glutamate in CeA. (e) Mean \pm SEM frequency, amplitude, rise, and decay of sEPSCs for CeA neurons from ethanol-dependent rats. Nociceptin significantly decreased (*significance at $P<0.05$ ) and the NOP antagonist significantly increased (*significance at $P<0.05)$ the mean sEPSC frequencies, indicating presynaptic actions of the nociceptin system on spontaneous glutamate release in CeA.

postsynaptic sites of action are also observed. Given our recording conditions (recording at RMP, no modified magnesium concentration), our CeA excitatory synaptic responses are mediated primarily by non-NMDA receptors (Roberto et al, 2004b).

In the context of nociceptin-ethanol interactions on evoked glutamatergic responses, acute ethanol also decreases CeA glutamatergic transmission (Roberto et al, 2004b). Although the nociceptin-induced decrease in evoked EPSP amplitudes was associated with a significant increase in PPF ratio, the ethanol-induced inhibition of EPSPs was not, indicating a presynaptic site of action for the peptide, but not for ethanol. Notably, in naive rats when nociceptin is applied first, it prevents the ethanol-induced inhibition, and when ethanol is applied first, it occludes the nociceptin-induced decrease in glutamatergic transmission. Thus, the occlusion effects observed with the combined drugs are likely due to nociceptin-induced presynaptic inhibition of glutamate release, which consequently impairs postsynaptic responses and ethanol's ability to modulate 
them. Conversely, ethanol-induced postsynaptic inhibition of EPSPs likely masks the ability to detect nociceptin's presynaptic effects on glutamate release. However, we cannot rule out that these drugs target common mechanisms at postsynaptic sites, because the order of drug (ethanol and nociceptin) application does not affect the reciprocal blockade of glutamate transmission and the magnitude of the ethanol-induced glutamatergic inhibition is comparable to that of nociceptin. In this case, it is possible that ethanol and/or nociceptin (whichever is applied first) blocks postsynaptic glutamate receptors, preventing channel opening upon ligand binding and masking changes in presynaptic glutamate release. Although nociceptin-induced increases in PPF ratios suggest a decreased probability of transmitter release (Mennerick and Zorumski, 1995; Salin et al, 1996), these effects may be concurrent with postsynaptic mechanisms under some conditions (Wang and Kelly, 1997).

In the ethanol-dependent rats, ethanol postsynaptically decreases evoked EPSPs (Roberto et al, 2004b), and also decreases PPF ratios (suggesting increased glutamate release) and nociceptin still prevented the ethanol-induced inhibition of these evoked responses. Thus, owing to the occlusive interaction between nociceptin and ethanol, we speculate that the target mechanisms between these two agents in CeA neurons of ethanol-dependent rats are likely at a presynaptic site. These combined results indicate a complex cellular mechanism that underlies the effects of ethanol and nociceptin on evoked EPSPs.

Finally, application of the NOP antagonist revealed tonic NOP facilitatory activity on spontaneous glutamate release, but not evoked glutamatergic activity in the CeA of naive rats, suggesting tonic activity of endogenous nociceptin signaling only on spontaneous transmission. Pretreatment of CeA neurons with the NOP antagonist blocked the nociceptin-induced inhibition of evoked EPSP amplitudes, indicating that nociceptin exerts its effect through NOPs. Notably, NOP antagonism did not alter ethanol effects on evoked EPSPs, suggesting that these receptors do not mediate ethanol inhibition of glutamatergic transmission in the CeA.

Impaired glutamatergic neurotransmission represents a primary molecular mechanism underlying long-term effects of chronic alcohol consumption (Lovinger et al, 2013; Roberto et al, 2004b, 2006a). Thus, we also investigated the effects of chronic ethanol on the nociceptin/NOP system and glutamatergic transmission within the CeA. Here, we report that in ethanol-dependent rats, the nociceptin inhibitory effects on both evoked and spontaneous glutamate transmission were similar to those observed in naive animals.

Although counterintuitive, the lack of overall difference of exogenously applied nociceptin on glutamatergic transmission in ethanol-dependent animals, compared with naive animals, suggests a fundamental functional role of the nociceptin system in the maintenance of homeostasis. On the basis of our data of evoked glutamatergic responses, the NOP antagonist significantly increased glutamatergic responses only in ethanol-dependent rats, suggesting increased NOP levels/functions after chronic ethanol and revealing a tonic inhibitory action at the $\mathrm{CeA}$ glutamatergic synapses. We hypothesize that basal NOP activity in the $\mathrm{CeA}$ is generated by endogenous nociceptin tone that diminishes local glutamate release to dampen local excitation and local inhibition as reported previously (Cruz et al, 2012; Roberto and Siggins, 2006b). Importantly, NOP mRNA expression and NOP binding sites are highly enriched in the amygdala (Andero et al, 2013). Nociceptin reduces GABAergic transmission in the $\mathrm{CeA}$ via decreased presynaptic GABA release, and prevents and totally reverses the acute ethanol-induced increases in GABA release (Roberto and Siggins, 2006b). In the CeA from alcoholdependent rats, the depressant effect of nociceptin is significantly stronger than in those from naive rats, suggesting that the nociceptin system regulating GABAergic synapses adapts during chronic alcohol exposure (Roberto and Siggins, 2006b; see Supplementary Figure 2B). Nociceptin also blocks the CRF-induced increase of GABA release via the presynaptic PKA pathway, a common signaling pathway that is targeted in opposing directions by nociceptin and CRF to regulate GABA release (Cruz et al, 2012). On the basis of these data on glutamate and our previous work on nociceptin effects on GABAergic transmission, it seems reasonable to assume a functional 'fine tuning' role of nociceptin/NOP system in the amygdala in the development of ethanol dependence and other anxiety disorders (Andero et al, 2013).

Alcoholism represents a significant health and economic burden with a limited number of effective therapeutic options. One currently available clinical treatment is acamprosate (Campral) (De Witte et al, 2005; Koob et al, 2002; Mann et al, 2008), which is thought to stabilize the disrupted chemical balance in the alcoholic brain, possibly by antagonizing glutamatergic receptors. Thus, the development of additional therapeutics such as an NOP agonist may represent a novel potential target for treating alcohol dependence.

\section{FUNDING AND DISCLOSURE}

This is manuscript number 25061 from The Scripps Research Institute. The following organizations have provided financial compensation for professional services to: Marsida Kallupi: School of Pharmacy, Pharmacology Unit, University of Camerino, Via Madonna delle Carceri, 62032 Camerino, Italy, Florence Varodayan, Christopher Oleata, George Luu, and Marisa Roberto: NIH Grants AA015566, AA06420, AA016985, AA017447, AA021491, and AA013498. Diego Correia: Department of Pharmacology, Universidade Federal do Paraná, Jardim das Américas, Curitiba, Paraná, CEP 81531-990; Brazil. The authors declare no conflict of interest.

\section{ACKNOWLEDGEMENTS}

We thank Dr ML Logrip (The Scripps Research Institute, La Jolla, CA) for help in the preparation of this manuscript.

\section{REFERENCES}

Andero R, Brothers SP, Jovanovic T, Chen YT, Salah-Uddin H, Cameron $\mathrm{M}$ et al (2013). Amygdala-dependent fear is regulated by Oprl1 in mice and humans with PTSD. Sci Transl Med 5: 173-188. 
Andreasen M, Hablitz JJ (1994). Paired-pulse facilitation in the dentate gyrus: a patch-clamp study in rat hippocampus in vitro. J Neurophysiol 72: 326-336.

Calo G, Guerrini R, Rizzi A, Salvadori S, Regoli D (2000). Pharmacology of nociceptin and its receptor: a novel therapeutic target. Br J Pharmacol 129: 1261-1283.

Ciccocioppo R, Angeletti S, Panocka I, Massi M (2000). Nociceptin/ orphanin FQ and drugs of abuse. Peptides 21: 1071-1080.

Ciccocioppo R, Economidou D, Fedeli A, Angeletti S, Weiss F, Heilig $\mathrm{M}$ et al (2004). Attenuation of ethanol self-administration and of conditioned reinstatement of alcohol-seeking behaviour by the antiopioid peptide nociceptin/orphanin FQ in alcoholpreferring rats. Psychopharmacology (Berl) 172: 170-178.

Ciccocioppo R, Economidou D, Fedeli A, Massi M (2003). The nociceptin/orphanin $\mathrm{FQ} / \mathrm{NOP}$ receptor system as a target for treatment of alcohol abuse: a review of recent work in alcoholpreferring rats. Physiol Behav 79: 121-128.

Cruz MT, Herman MA, Kallupi M, Roberto M (2012). Nociceptin/ orphanin FQ blockade of corticotropin-releasing factor-induced gamma-aminobutyric acid release in central amygdala is enhanced after chronic ethanol exposure. Biol Psychiatry 71: 666-676.

Darland T, Heinricher MM, Grandy DK (1998). Orphanin FQ/ nociceptin: a role in pain and analgesia, but so much more. Trends Neurosci 21: 215-221.

De Koninck Y, Mody I (1994). Noise analysis of miniature IPSCs in adult rat brain slices: properties and modulation of synaptic GABAA receptor channels. J Neurophysiol 71: 1318-1335.

De Witte P, Littleton J, Parot P, Koob G (2005). Neuroprotective and abstinence-promoting effects of acamprosate: elucidating the mechanism of action. CNS Drugs 19: 517-537.

Eckardt MJ, File SE, Gessa GL, Grant KA, Guerri C, Hoffman PL et al (1998). Effects of moderate alcohol consumption on the central nervous system. Alcohol Clin Exp Res 22: 998-1040.

Emmerson PJ, Miller RJ (1999). Pre- and postsynaptic actions of opioid and orphan opioid agonists in the rat arcuate nucleus and ventromedial hypothalamus in vitro. J Physiol (Lond) 517(Part 2): 431-445.

Gompf HS, Moldavan MG, Irwin RP, Allen CN (2005). Nociceptin/ orphanin FQ (N/OFQ) inhibits excitatory and inhibitory synaptic signaling in the suprachiasmatic nucleus (SCN). Neuroscience 132: 955-965.

Henderson G, McKnight AT (1997). The orphan opioid receptor and its endogenous ligand-nociceptin/orphanin FQ. Trends Pharmacol Sci 18: 293-300.

Herman MA, Contet C, Justice NJ, Vale W, Roberto M (2013). Novel subunit-specific tonic GABA currents and differential effects of ethanol in the central amygdala of CRF receptor-1 reporter mice. J Neurosci 33: 3284-3298.

Jenck F, Moreau JL, Martin JR, Kilpatrick GJ, Reinscheid RK, Monsma FJ Jr. et al (1997). Orphanin FQ acts as an anxiolytic to attenuate behavioral responses to stress. Proc Natl Acad Sci USA 94: 14854-14858.

Koob GF (2008). A role for brain stress systems in addiction. Neuron 59: 11-34.

Koob GF, Le Moal M (2001). Drug addiction, dysregulation of reward, and allostasis. Neuropsychopharmacology 24: 97-129.

Koob GF, Le Moal M (2008). Addiction and the brain antireward system. Annu Rev Psychol 59: 29-53.

Koob GF, Mason BJ, De Witte P, Littleton J, Siggins GR (2002). Potential neuroprotective effects of acamprosate. Alcohol Clin Exp Res 26: 586-592.

Koob GF, Roberts AJ, Schulteis G, Parsons LH, Heyser CJ, Hyytia P et al (1998). Neurocircuitry targets in ethanol reward and dependence. Alcohol Clin Exp Res 22: 3-9.

Krettek JE, Price JL (1978). A description of the amygdaloid complex in the rat and cat with observations on intra-amygdaloid axonal connections. J Comp Neurol 178: 255-280.
Kuzmin A, Kreek MJ, Bakalkin G, Liljequist S (2007). The nociceptin/orphanin FQ receptor agonist Ro 64-6198 reduces alcohol self-administration and prevents relapse-like alcohol drinking. Neuropsychopharmacology 32: 902-910.

Kuzmin A, Sandin J, Terenius L, Ogren SO (2003). Acquisition, expression, and reinstatement of ethanol-induced conditioned place preference in mice: effects of opioid receptor-like 1 receptor agonists and naloxone. J Pharmacol Exp Ther 304: 310-318.

Lambert DG (2008). The nociceptin/orphanin FQ receptor: a target with broad therapeutic potential. Nat Rev Drug Discov 7: $694-710$

Liebel JT, Swandulla D, Zeilhofer HU (1997). Modulation of excitatory synaptic transmission by nociceptin in superficial dorsal horn neurones of the neonatal rat spinal cord. $\mathrm{Br}$ J Pharmacol 121: 425-432.

Lovinger DM, Roberto M (2013). Synaptic effects induced by alcohol. In: Sommer WHSpanagel R (eds) Current Topics in Behavioral Neurosciences Vol. 13 (Springer: Berlin-Heidelberg), pp 31-86.

Manabe T, Wyllie D, Perkel DJ, Nicoll RA (1993). Modulation of synaptic transmission and long-term potentiation in the CA1 region of the hippocampus. J Neurophysiol 70: 1451-1459.

Mann K, Kiefer F, Spanagel R, Littleton J (2008). Acamprosate: recent findings and future research directions. Alcohol Clin Exp Res 32: 1105-1110.

Martin-Fardon R, Ciccocioppo R, Massi M, Weiss F (2000). Nociceptin prevents stress-induced ethanol- but not cocaineseeking behavior in rats. NeuroReport 11: 1939-1943.

Martin-Fardon R, Zorrilla EP, Ciccocioppo R, Weiss F (2010). Role of innate and drug-induced dysregulation of brain stress and arousal systems in addiction: focus on corticotropin-releasing factor, nociceptin/orphanin FQ, and orexin/hypocretin. Brain Res 1314: 145-161.

Meis S, Munsch T, Pape HC (2002). Antioscillatory effects of nociceptin/orphanin $\mathrm{FQ}$ in synaptic networks of the rat thalamus. J Neurosci 22: 718-727.

Meis S, Pape HC (2001). Control of glutamate and GABA release by nociceptin/orphanin FQ in the rat lateral amygdala. J Physiol 532(Part 3): 701-712.

Mennerick S, Zorumski CF (1995). Paired-pulse modulation of fast excitatory synaptic currents in microcultures of rat hippocampal neurons. J Physiol 488(Part 1): 85-101.

Meunier JC (1997). Nociceptin/orphanin FQ and the opioid receptor-like ORL1 receptor. Eur J Pharmacol 340: 1-15.

Miller RJ (1998). Presynaptic receptors. Annu Rev Pharmacol Toxicol 38: 201-227.

Mogil JS, Pasternak GW (2001). The molecular and behavioral pharmacology of the orphanin FQ/nociceptin peptide and receptor family. Pharmacol Rev 53: 381-415.

Neal CR Jr., Mansour A, Reinscheid R, Nothacker HP, Civelli O, Akil $\mathrm{H}$ et al (1999). Opioid receptor-like (ORL1) receptor distribution in the rat central nervous system: comparison of ORL1 receptor mRNA expression with (125)I-[(14)Tyr]-orphanin FQ binding. J Comp Neurol 412: 563-605.

Otis TS, De Koninck Y, Mody I (1994). Lasting potentiation of inhibition is associated with an increased number of gammaaminobutyric acid type A receptors activated during miniature inhibitory postsynaptic currents. Proc Natl Acad Sci USA 91: 7698-7702.

Pich EM, Lorang M, Yeganeh M, Rodriguez de Fonseca F, Raber J, Koob GF et al (1995). Increase of extracellular corticotropinreleasing factor-like immunoreactivity levels in the amygdala of awake rats during restraint stress and ethanol withdrawal as measured by microdialysis. J Neurosci 15: 5439-5447.

Pitkanen A, Stefanacci L, Farb CR, Go GG, LeDoux JE, Amaral DG (1995). Intrinsic connections of the rat amygdaloid complex: projections originating in the lateral nucleus. J Comp Neurol 356: $288-310$ 
Rassnick S, Heinrichs SC, Britton KT, Koob GF (1993). Microinjection of a corticotropin-releasing factor antagonist into the central nucleus of the amygdala reverses anxiogenic-like effects of ethanol withdrawal. Brain Res 605: 25-32.

Reinscheid RK, Nothacker HP, Bourson A, Ardati A, Henningsen RA, Bunzow JR et al (1995). Orphanin FQ: a neuropeptide that activates an opioidlike G protein- coupled receptor. Science 270: 792-794.

Roberto M, Bajo M, Crawford E, Madamba SG, Siggins GR (2006a). Chronic ethanol exposure and protracted abstinence alter NMDA receptors in central amygdala. Neuropsychopharmacology 31: 988-996.

Roberto M, Cruz MT, Gilpin NW, Sabino V, Schweitzer P, Bajo M et al (2010). Corticotropin releasing factor-induced amygdala gamma-aminobutyric acid release plays a key role in alcohol dependence. Biol Psychiatry 67: 831-839.

Roberto M, Gilpin NW, Siggins GR (2012). The central amygdala and alcohol: role of gamma-aminobutyric acid, glutamate, and neuropeptides. Cold Spring Harb Perspect Med 2: a012195.

Roberto M, Madamba SG, Moore SD, Tallent MK, Siggins GR (2003). Ethanol increases GABAergic transmission at both pre- and postsynaptic sites in rat central amygdala neurons. Proc Natl Acad Sci USA 100: 2053-2058.

Roberto M, Madamba SG, Stouffer DG, Parsons LH, Siggins GR (2004a). Increased GABA release in the central amygdala of ethanol-dependent rats. J Neurosci 24: 10159-10166.

Roberto M, Schweitzer P, Madamba SG, Stouffer DG, Parsons LH, Siggins GR (2004b). Acute and chronic ethanol alter glutamatergic transmission in rat central amygdala: an in vitro and in vivo analysis. J Neurosci 24: 1594-1603.

Roberto M, Siggins GR (2006b). Nociceptin/orphanin FQ presynaptically decreases GABAergic transmission and blocks the ethanol-induced increase of GABA release in central amygdala. Proc Natl Acad Sci USA 103: 9715-9720.

Roberts AJ, Cole M, Koob GF (1996). Intra-amygdala muscimol decreases operant ethanol self-administration in dependent rats. Alcohol Clin Exp Res 20: 1289-1298.

Rogers J, Wiener SG, Bloom FE (1979). Long-term ethanol administration methods for rats: advantages of inhalation over intubation or liquid diets. Behav Neural Biol 27: $466-486$.
Salin PA, Scanziani M, Malenka RC, Nicoll RA (1996). Distinct short-term plasticity at two excitatory synapses in the hippocampus. Proc Natl Acad Sci USA 93: 13304-13309.

Savander V, Go CG, LeDoux JE, Pitkanen A (1995). Intrinsic connections of the rat amygdaloid complex: projections originating in the basal nucleus. J Comp Neurol 361: 345-368.

Schank JR, Ryabinin AE, Giardino WJ, Ciccocioppo R, Heilig M (2012). Stress-related neuropeptides and addictive behaviors: beyond the usual suspects. Neuron 76: 192-208.

Tallent MK (2008). Presynaptic inhibition of glutamate release by neuropeptides: use-dependent synaptic modification. Inhibit Regul Excit Neurotransm 44: 177-200.

Tallent MK, Madamba SG, Siggins GR (2001). Nociceptin reduces epileptiform events in CA3 hippocampus via presynaptic and postsynaptic mechanisms. J Neurosci 21: 6940-6948.

Ubaldi M, Bifone A, Ciccocioppo R (2013). Translational approach to develop novel medications on alcohol addiction: focus on neuropeptides. Curr Opin Neurobiol 23: 684-691.

Van der Kloot W (1991). The regulation of quantal size. Prog Neurobiol 36: 93-130.

Vaughan CW, Ingram SL, Connor MA, Christie MJ (1997). How opioids inhibit GABA-mediated neurotransmission (see comments). Nature 390: 611-614.

Wang JH, Kelly PT (1997). Attenuation of paired-pulse facilitation associated with synaptic potentiation mediated by postsynaptic mechanisms. J Neurophysiol 78: 2707-2716.

Wu LG, Saggau P (1994). Presynaptic calcium is increased during normal synaptic transmission and paired-pulse facilitation, but not in long-term potentiation in area CA1 of hippocampus. J Neurosci 14: 645-654.

Wu LG, Saggau P (1997). Presynaptic inhibition of elicited neurotransmitter release. Trends Neurosci 20: 204-212.

Yu B, Shinnick-Gallagher P (1998). Corticotropin-releasing factor increases dihydropyridine- and neurotoxin-resistant calcium currents in neurons of the central amygdala. J Pharmacol Exp Ther 284: 170-179.

Yu TP, Fein J, Phan T, Evans CJ, Xie CW (1997). Orphanin FQ inhibits synaptic transmission and long-term potentiation in rat hippocampus. Hippocampus 7: 88-94.

Zeilhofer HU, Selbach UM, Guhring H, Erb K, Ahmadi S (2000). Selective suppression of inhibitory synaptic transmission by nocistatin in the rat spinal cord dorsal horn. J Neurosci 20: 4922-4929.

Supplementary Information accompanies the paper on the Neuropsychopharmacology website (http://www.nature.com/npp) 